\title{
An Ex-Ante Evaluation for Solid Waste Treatment Facilities using LCCA
}

\author{
Dima Jawad \\ Department of Civil and Environmental Engineering, Notre Dame University-Louaize, \\ ZoukMosbeh, Lebanon
}

\begin{abstract}
The application of Life Cycle Cost Analysis (LCCA) in infrastructure facilities projects has been marginalised so far especially in real-life projects. In many cases, the significance of this tool is not the end result by itself but the improvements that can be made to the infrastructure facility design during and as a result of the LCCA model development. This paper presents lessons-learnt from analysing and developing a LCCA model for an actual integrated municipal solid waste management infrastructure facility using the anaerobic treatment technology and recycling. The development of the LCCA model for the facility involved several distinctive steps such as system analysis and disintegration, maintenance and operation cost data acquisition, identifying relevant performance indicators for each operation that can be utilized in tandem with the LCCA model, setting up serviceability threshold for each operation. In addition to model development description, the paper highlights the requirements needed and the impediments that may be encountered when developing LCCA model for solid waste management facilities. At the end, the paper concludes with providing recommendations for decision makers and researchers in this field based on the experience gained from the model development.
\end{abstract}

\section{KEYWORDS}

Life Cycle Cost Analysis, municipal solid waste treatment, anaerobic digestion

\section{INTRODUCTION}

In cities of developing countries nowadays, almost every municipal manager is faced with the mounting crisis of solid waste disposal. Concurrently, these decision makers are bombarded with proposals from the developed-world corporations or entrepreneurs that promise them the "optimal" and forward-looking solution for their solid waste crisis by encouraging them to utilize novel technologies and latest research in this field. In many cases, these technologies have not been implemented in city-scale real practice long enough to assess their long-term social, environmental and economic impacts. Decisions related to erecting and managing infrastructure facilities (especially when adopting innovative technologies) that impact our lives and the lives of future generation are of utmost importance and must be based on conversant and informed support and proper assessment that takes into account all factors and parameters pertaining to the problem and solution. Many inter-disciplinary evaluation tools and concepts must be opened up, integrated, and deployed resourcefully. Among these concepts is Life Cycle Cost Analysis (LCCA). This concept had been always acknowledged as an indispensable decision-support tool for achieving sustainable infrastructures due to its capability to capture the long-term impacts of infrastructure facilities[1],[2].

This paper presents an ex-ante evaluation through analysing and developing a LCCA model for an actual proposed project in Lebanon. The project is an integrated municipal solid waste management facility (IMSWF) using novel technologies in anaerobic treatment and recycling. 
Civil Engineering and Urban Planning: An International Journal(CiVEJ) Vol.2,No.4, December 2015

The development of the LCCA model for the facility involved several distinctive steps such as system analysis and disintegration, cost data acquisition, deciding on maintenance and upgrading strategies, analyzing results and identifying relevant performance indicators that can be utilized in tandem with the LCCA model. The paper starts with description of the facility, presenting the theory behind LCCA, discussing the data acquisition and model development, analyzing results and introducing potential performance indicators. The paper concludes with providing recommendations for decision makers and researchers in this field based on the experience gained from the model development.

\section{DESCRIPTION OF THE FACILITY}

The proposed project is planned to treat 300 tons per day of mixed municipal solid waste transported daily to the facility. The waste mix includes house garbage, tree leaves, grass, wholesale vegetable market waste, metals, paper, card board, plastic and whatever is reasonably described as household waste.

The treatment concept of IMSWF consists of two major procedures: mechanical pre-treatment and biological treatment using anaerobic digestion technology. The main goals for the facility are1) minimize solid waste quantity going to landfills; 2) salvage and utilize solid waste recyclables, and 3) make the most of produced biogas (as electricity) and treated organic waste (as fertilizers).

\section{Provided that IMSWF operated as designed, its end-products shall be as follows:}

- Fertilizer end-product - about 45,000 tons/year with 50\% dry solids content.

- Biogas - about $108,000 \mathrm{~m}^{3} /$ week with average Methane and Carbon Dioxide contents of $56 \%$ and $44 \%$ respectively.

- Recyclables - as per incoming waste composition.

The IMSWF comprised particular integrated processes: mechanical treatment, wet mechanical organic waste treatment, anaerobic digestion process, wet aerobic stabilization, dewatering, water management, waste air treatment, and plant automation. The first three are the main processes while the remaining processes supplement the main ones. Only a brief description of the main processes is given next.

\section{The Mechanical Treatment}

There are a variety of pre-treatment processes that can be chosen based on the characteristics of the incoming waste and the effects they have on digestion[3]. The mechanical treatment process chosen for IMSWFexecutes two core functions:

- sorting and separation of inorganic recyclables (37\%) such as paper/cardboard, plastics, metal...etc

- size reduction of the organic matter $(60 \%)$ by shredding and crushing to prepare the required organic rich waste fraction that will be treated anaerobically

\section{Wet Mechanical Organic Waste Treatment}

The organic rich waste fraction which is the output of the mechanical treatment is the input to the wet mechanical waste treatment. This segment of the facility entails the preparation of the suspension that is fed to the digesters for the anaerobic treatment.The fine fraction produced within the mechanical treatment is fed by belt conveyors to two feed preparation tanks (FPT), where it is transformed into a liquid suspension by adding processed water, coming from the dewatering equipment, and fresh water. 


\section{Digestion Process}

The digestion process for biowaste treatment is an anaerobic process (ie, the decomposition of organic material by micro-organisms in an oxygen depleted environment yielding the production of biogas) in completely closed tanks without any air and light. The mean residence time of biosuspension in the reactor is calculated as $20-23$ days for an optimal degradation rate which is achieved at the thermophilic temperature of $55^{\circ} \mathrm{C}$. Consequently, to treat the amount of the organic solid waste received daily at the facility, two digesting tanks are needed. These tanks are concrete structures of $7200 \mathrm{~m}^{3}$ total volume, $29 \mathrm{~m}$ height and $19 \mathrm{~m}$ inner diameter.

Every day the digester is fed to the maximum level of $27 \mathrm{~m}$. Suspension or sludge prepared in the feed preparation tanks is pumped and mixed with a certain amount of recycled sludge from the digesters. The resulting sludge mix passes an inline heat exchanger to raise the sludge temperature to the thermophilic temperature level. The heated sludge is then pumped into the digesters.

As for the biogas formed during the digestion process, it is taken from the digester throughout the gas dome at the top of the digester to the gas storage tank. It will contain methane (average 56\%) and carbon dioxide (average $31 \%$ ) as main components.

The resulting digested sludge will go through wet aerobic stabilization to produce ammonia in liquid form, then to dewatering process to produce fresh fertilizer with solid content of $30 \%-50 \%$.

The MSW plant is fully automated and monitored by a central computer system. Each process is controlled by a "Programmable Logic Controller" (PLC); data from these PLCs are remotely monitored and adjusted from the central computer system. A network of fiber optics is used to communicate data from sensors connected to individual PLC's to the central computer system.

\section{LIFE CYCLE COST ANALYSIS}

The realization that the true cost of a facility does not end by the completion of the construction is becoming more apparent these days. Facilities' owners are day-by-day comprehending the fact that the owning and operating costs include, in addition to the initial acquisition and construction costs, the running, labor, energy, maintenance and rehabilitation costs[4]. Additionally, the fact that infrastructure facilities generally have long service lifetimes, and since maintenance activities have long been based solely on staff experience and ad-hoc measures, the quality of performance has been dropping due to aging,overuse, mismanagement or neglect and resulting in catastrophic failures and sometimes loss of life[5]; [6].All these realities have led to the realization that performingLCCA in conjunction withcontinuous monitoring, and periodic condition assessment over the facility's life is indispensable[7].

LCCA, a member of the economic evaluation tools, refers to the phased process of estimating the total discounted dollar cost of purchasing, owning, operating, and maintaining an asset over a period of time: the net present value. The estimation is done according equation (1).

$$
N P V=C C+\sum_{t=0}^{T} \frac{(O C+M C+R C-S V)}{(1+r)^{t}}
$$

Where: NPV $=$ Net Present Value; $\mathrm{t}=$ Time period (i.e., year); $\mathrm{T}=$ Analysis Period (years); $\mathrm{r}=$ RealDiscount Rate (decimals), $\mathrm{CC}=$ Capital Cost, $\mathrm{OC}=$ Operating Cost, $\mathrm{MC}=$ Maintenance Cost, $\mathrm{RC}=$ Rehabilitation Cost, $\mathrm{SV}=$ Salvage Value

LCCA can be implemented at any stage of the planning process and can also be an effective tool for evaluation of existing assets and infrastructure [8]. In addition to equation (1), the following LCCA parameters are defined. 


\section{Analysis Period}

Hudson et. Al[6] define the analysis period as "the period in years over which a building, component, or subsystem provides adequate performance fulfilling the purpose for which it was built or acquired. It is a technical parameter, different from economic life, which depends on design, construction quality, operations and maintenance practices, use, and environmental factors." Many methods are introduced for determining the analysis period such as survivor curve method, performance modeling, accelerated testing and reference to previous experience.

\section{Economic parameters}

The interest rate $(i)$ which reflects the investor's time value of money or opportunity cost. The inflation rate $(f)$. The discount rate $(r)$ which is calculated as in equation (2).

$$
r=\frac{i-f}{1+f}
$$

\section{Capital Costs:}

The first component in an LCCA equation is capital costs. Capital costs, or initial expenses, include all costs incurred prior to the operation of the infrastructure.

\section{Annual Operating Costs:}

The operation costs are annual costs, excluding maintenance and repair costs, involved in the operation of the infrastructure or facility. Most of these costs are related to energy, supplies, utilities and labor.

\section{Annual Maintenance and Repairs Costs}

Maintenance costs are scheduled costs associated with the upkeep of the infrastructure or facility. Repair costs are unanticipated expenditures that are required to prolong the life of the facility without replacing the system.

\section{Non-Annual Replacement, Upgrade, or RehabilitationCosts:}

Replacement costs are anticipated expenditures to major components of the infrastructure that are required to maintain operation of the infrastructure or facility.

\section{Salvage Value:}

The expected value of the facility at the end of the analysis period[9].

\section{LCCA MODEL DEVELOPMENT \& DATA COLLECTION}

This section describes the development of IMSWF LCC model. This model excluded the mechanical treatment process for impediments in cost dataacquirementat that time.

Every input parameter in the LCCA model needs to be acknowledged and reckoned.To achieve this, many sources were utilized in the data collection process to ensure the consistency of the information used in building the model. These sources included: procurement departments at various related enterprises, maintenance and operation manuals of equipment and machinery provided by the relevant manufacturers or suppliers, working experience of the O\&M teams at similar plants in Europe, and the expertiseof the "IMSWF Project" design and contractors" teams, local experts. 
Civil Engineering and Urban Planning: An International Journal(CiVEJ) Vol.2,No.4, December 2015

Table 1- Sample of Maintenance Procedures Collected

\begin{tabular}{|c|c|c|}
\hline Equipment & Maintenance Procedure & Frequency \\
\hline \multirow{3}{*}{ Filters } & Condensate purging & Weekly \\
\hline & Changing filter media & Quarterly \\
\hline & Checking for leaks and changing gaskets & 5 Years \\
\hline \multirow{4}{*}{ Sludge Pumps } & Check for leaks, vibration and noise & Monthly \\
\hline & Change mechanical seal, couplings & 3 Years \\
\hline & Change rotor & 6 Years \\
\hline & Change pump & 12 Years \\
\hline \multirow[t]{3}{*}{ Air compressor } & $\begin{array}{l}\text { Check oil, pressure switches, leaks, noise drain } \\
\text { tank. }\end{array}$ & Monthly \\
\hline & Change oil and belts & Yearly \\
\hline & Change air compressor unit & 10 Years \\
\hline \multirow[t]{2}{*}{$\begin{array}{l}\text { Sludge heat } \\
\text { exchangers }\end{array}$} & Check for leaks and purge air & Semi Annually \\
\hline & Drain and clean & Yearly \\
\hline
\end{tabular}

Following a thorough analysis of the "anaerobic digestion" process described above, it was found best to subdivide the overall process into its major flow lines which result in the final deliverables:Gas-Flow Line, Sludge-Flow Line, Heating-Flow Line, Process-Water Flow Line, and Diesel Line.In addition to the above sub-processes, electrical power\& automation and structures divisions were also considered. This grouping enabled the listing of all equipment and machinery (except pipes) required in each sub-process - as discovered from itsflow diagramwhich allowed data items to be identified easily and later to apply the systematic computation of the model.

For every item in each sub-process, parameters related to initial cost, preventive maintenance activities cost and timing, upgrading/replacement costs and timing were obtained. A sample of the collected data for the required maintenance activities of the different machinery is presented in Table (1).

Annual operating costs that are related to recurrent expenditures on consumables and similar were acknowledged and estimated. Labor teams needed for every process, were determined and corresponding man-hours were assigned as in Table (2).For this reason, the labor hours required for the functioning of the different maintenance activities were gathered as well as the estimation of the necessary number of operating teams and their cost. 
Table 2 - Sample ofthe resultant Labour Hours per Process for the first three years

\begin{tabular}{|c|c|c|c|c|c|c|}
\hline \multicolumn{7}{|c|}{ Total Labour Hours per Process } \\
\hline Years & $\begin{array}{c}\text { Gas } \\
\text { Process }\end{array}$ & $\begin{array}{c}\text { Sludge } \\
\text { Process }\end{array}$ & $\begin{array}{c}\text { Heating } \\
\text { Process }\end{array}$ & $\begin{array}{c}\text { Process } \\
\text { Water } \\
\text { Process }\end{array}$ & $\begin{array}{c}\text { Diesel } \\
\text { Process }\end{array}$ & $\begin{array}{c}\text { Total } \\
\text { hours }\end{array}$ \\
\hline 1 & 1,630 & 2,102 & 1,214 & 229 & 50 & 5,225 \\
\hline 2 & 1,630 & 2,102 & 1,262 & 247 & 50 & 5,291 \\
\hline 3 & 1,630 & 2,222 & 1,298 & 277 & 50 & 5,477 \\
\hline
\end{tabular}

After preliminary data collection was concluded, every data point waskeyed inthe respective cell of several interrelated data sheets (excel) each corresponded to certain sub-process and its cells corresponded todifferent activity types (ie, acquisition, maintenance, upgrading, operating, replacement) and timing. Revisions and brainstorming sessions were held after all data were input. The sessionsincluded experts representing main suppliers, contractors, and design teams. The main purpose behind these sessions was to expose any facts, historical records, operational experience regarding contingencies that might aid in the analysis and the uncovering of the performance indicators or contingency plans if required.

\section{Economic Parameters and Analysis Period}

Deciding on what are the values for the economic parameters to be used in the calculation of the Net Present Value of the facility is dependent on many factors related to economic conditions in the country or the region. After consulting the owners regarding the potential opportunity cost of their investment, the interest rate was set at $18.9 \%$. Inflation rate was set at $4 \%$. Therefore, the value of the real interest rate (discount rate) was calculated to be $14.3 \%$.

The analysis period is a very important parameter in LCCA due to its extreme sensitivity. For IMSWF, the analysis period was estimated at 20 years afterconsidering all factors.

\section{Model Results}

The total cost calculated per each sub-process was then calculated and plotted versus the 20 years' service-life. Consequently, the result was seven different graphs which will be integrated as part of the attempted LCC model. Figure (1) illustrates the chart of estimated real costs of operating and maintaining the facility over the 20 years analysis period

For the 20-years life cycle, operating and maintenance cost were estimated. These costs were discounted and summed up in addition to the initial capital cost to yield a net present value of the total LCC model as computed on the spreadsheet to be $\$ 13,077,673$ million. Figure (2) shows a plot of the total real cost of the facility over its life cycle. 
Civil Engineering and Urban Planning: An International Journal(CiVEJ) Vol.2,No.4, December 2015

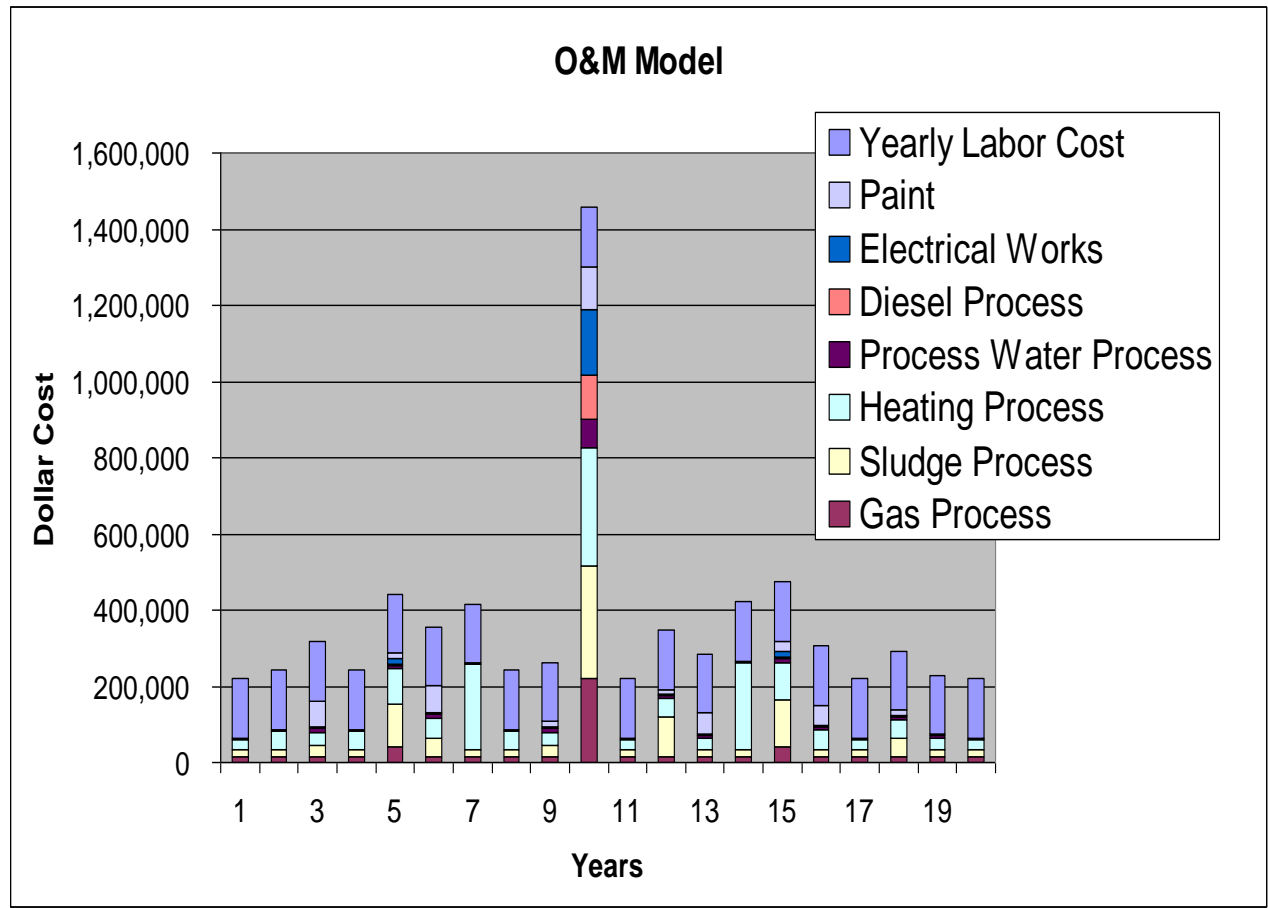

Figure 1 - Life-Cycle Operation and Maintenance Real Cost Model

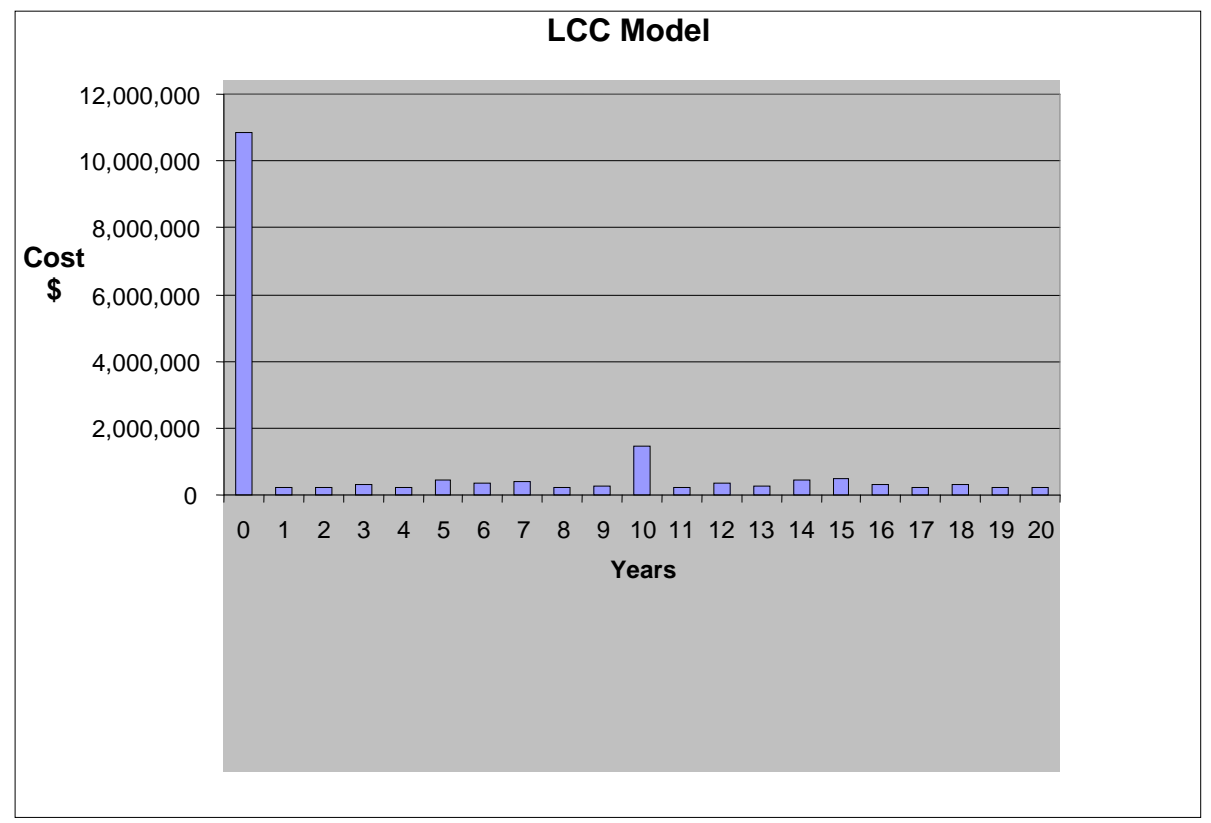

Figure 2 - Life-Cycle Total Real Cost Model of MSWF

\section{PERFORMANCE INDICATORS}

The inclusion of a performance measurement system to monitor the performance and success of any plant is of critical importance[10]. Moreover, pairing the performance measurement with lifecycle cost model that accounts for user and societal costs is an advanced step in LCCA development. This pairing is starting to appear in the practice of LCCA in other type of infrastructure facilities, in specific transportation facilities. 
After LCC model was developed, effort was put to identify performance indicators for the MSWF. These indicators must be related to the quality and quantity of the end-products and can be coupled with its LCCA model at some point. The MSWF staged an integrated waste management plan of three distinct solid waste treatment activities: sorting for recyclables (inorganic), anaerobic digestion of organic waste for producing electricity and fertilizers.

\section{An efficient performance measurement system must be able to:}

a. assess the performance of the waste treatment process as an essential requisite, and

b. Evaluate the outcomes from the process that have a direct or indirect effect on the anticipated rate of return either by their expected quantity/quality or through any projected improvement measures.

Consequently, the measurement system needs to include a set of informative and measurable performance indicators to determine the effectiveness of the waste treatment facility and the extent of meeting its specified objectives.

Below is a list of the potential performance indicators:

- Percent quantity of inert material (sent to landfill), probably this indicator is the most important as it relates to the main objective of building the facility which is the minimization of waste quantity sent to landfills.

- Fertilizer total quantity

- Fertilizer dry solids content

- Fertilizer impurity

- Total quantity of electrical energy

- Quantity of biogas flared

A minimum threshold for each one of the indicators can derived based on the incoming waste quantity and composition.

Finally, performance indicators together present a significant and concise overall picture of the facility's performance; they are used to report progress of critical success factors on the whole process. Developing a composite rating index from these indicators, similar to Pavement Serviceability Index (PSI) could be further investigated in future research work.

\section{CONCLUSION}

Developing a LCC model is an essential endeavor that must be undertaken for every infrastructure facility that is being planned, under construction or even operating. The benefits of this endeavor go beyond the textbook-stated objective of LCCA as identifying the project alternative with the lowest total life cycle cost. The process of performing the LCCA will heighten the understanding of the proposed project. The true benefits are gained during the process of developing the model itself rather than its end result. Criticaldefects or liabilities can be revealed; redesigns and fine tweaking can be made when it is still feasible. These benefits include, as a minimum, efficient asset management and long-term planning, identifying and employing optimal maintenance and rehabilitation strategies, decision support to resources allocation and budget planning, and support for financing application when needed. 
Civil Engineering and Urban Planning: An International Journal(CiVEJ) Vol.2,No.4, December 2015

\section{ACKNOWLEDGEMENTS}

The author acknowledgesthe work of Ms MerielleManokian during her thesis research at the American University in Beirut in the production of this paper.

\section{REFERENCES}

[1] C. Zurbrügg, M. Caniato and M. Vaccari, "How Assessment Methods Can Support Solid Waste Management in Developing Countries-A Critical Review," Sustainability, vol. 6, pp. 545-570, 2014.

[2] J. Walls and M. Smith, "Life-Cycle Cost Analysis in Pavement Design - Interim Technical Bulletin.," US Departemnet of Transportation, Federal Highway Adminstration, Washington, DC, 1998.

[3] k. Ostrem, Greening Waste: Anaerobic Digestion for Treating the Organic Fraction of Municipal Solid Wastes, New York: MS Thesis, Columbia University, 2004.

[4] D. Arditi and N. Messiha, "Life-Cycle Costing in Municipal Construction Projects," Journal of Infrastructure Systems, pp. 5-14, 1996.

[5] A. Lemer, "Infrastructure Obsolescence and Design Service Life," Journal of Infrastructure Systems, pp. 153-61, 1996.

[6] Hudson, Roland, Haas and Uddin, Infrastructure Management: Integrating Design, Construction, Maintenance, Rehabilitation, and Renovation, New York: McGraw-Hill, 1997.

[7] M. Manoukian, LCCA of an Infrastructure Project, Beirut: ME Thesis, American University of Beirut, 2006.

[8] Service Nova Scotia and Municipal Relations (SNSMR) at Province of Nova Scotia, "Municipal Infrastructure Asset Management Framework: Life Cycle Costing Analysis Tool Handbook," 2007. [Online]. Available: http://www.nsinfrastructure.ca/. [Accessed 20 June 2013].

[9] Education Support Services, "Life Cycle Cost Analysis Handbook," State of Alaska - Department of Education \& Early Development, Anchorage, 1999.

[10] Canadian International Development Agency, "Performance: Results-based Management in CIDA: An Introductory Guide to the Concepts and Principles," 2006. [Online]. Available: http://www.acdi-cida.gc.ca/. [Accessed 16 March 2014].

\section{AUTHORS}

DimaJawad is currently a faculty member at Notre Dame University - Louaize in Lebanon. She holds a PhD in Civil Engineering, MS in Urban Planning and BE in civil engineering. D. Jawadhas more than 9 years of experience in graduate and undergraduate teaching and research. Her area of research covers, economic evaluation of infrastructure projects, life cycle cost analysis,transportation engineering, sustainable urban development and sustainability education. She has also several years of experience in the industry, and has worked as a consultant for the public sector in areas of urban infrastructure and cultural heritage for the World Bank projects via the Council of Development and Reconstruction in Lebanon.

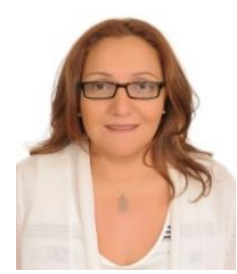

